\title{
Otolith chemistry of the non-dispersing reef fish Acanthochromis polyacanthus: cross-shelf patterns from the central Great Barrier Reef
}

\author{
Michael J. Kingsford ${ }^{1, *}$, Julian M. Hughes ${ }^{1,2}$, Heather M. Patterson ${ }^{1,3}$ \\ ${ }^{1}$ ARC Centre of Excellence for Coral Reef Studies and the School of Marine and Tropical Biology, JCU, Townsville, \\ Queensland 4811, Australia
}

${ }^{2}$ Present address: Fisheries Biology Unit, NSW Department of Primary Industries, Cronulla Fisheries Research Centre, PO Box 21 Cronulla, New South Wales 2230, Australia

${ }^{3}$ Present address: Fisheries and Marine Sciences Program, Bureau of Rural Sciences, GPO Box 858, Canberra, ACT 2601, Australia

\begin{abstract}
The influence of cross-shelf gradients, within and among distance strata, on the otolith chemistry of the non-dispersing reef fish Acanthochromis polyacanthus was examined on the Great Barrier Reef. Most of the variation in elemental ratios $(\mathrm{Mg} / \mathrm{Ca}, \mathrm{Cu} / \mathrm{Ca}, \mathrm{Sr} / \mathrm{Ca}, \mathrm{Ba} / \mathrm{Ca})$ was at the level of sites within reefs; some broad patterns of otolith chemistry were found cross-shelf. Sr/Ca and $\mathrm{Ba} / \mathrm{Ca}$ ratios increased with distance from shore. Highest ratios of $\mathrm{Mn} / \mathrm{Ca}$ and $\mathrm{Cu} / \mathrm{Ca}$ were found at the outermost shelf sites at Myrmidon Reef, but Mn levels were generally greatest within $45 \mathrm{~km}$ of shore. Elevated ratios of Ba/Ca at Myrmidon Reef were persistent over 3 yr and are likely indicative of upwelling, which is known to occur in the area. The $\mathrm{Ba} / \mathrm{Ca}$ ratios were the highest ever reported in marine fish otoliths, and accuracy of our estimates was confirmed in a paired laboratory test. The robustness of reef-wide chemical signatures in fish was weak, but unique signatures were found within reefs. High resolution elemental records could help to identify sites affected by upwelling and the periodicity of upwelling events.
\end{abstract}

KEY WORDS: Reef fish · Otolith chemistry - Inductively coupled plasma-mass spectrometry ICP-MS · Great Barrier Reef · Cross-shelf gradients · Upwelling

\section{INTRODUCTION}

Understanding patterns of dispersal is critical for population studies of fishes. Dispersal during the presettlement phase is particularly important for reef fishes, the majority of which are small and sedentary once they settle (Munday \& Jones 1998). Knowing the source of juveniles is critical for environmental managers who deal with numerous impacts on reefs, including sedimentation and pollution (McCulloch et al. 2003), disease (Harvell et al. 2002), over-harvesting (Jackson et al. 2001, Myers \& Worm 2003, Pandolfi et al. 2003) and climate change (Gardner et al. 2003, Hughes et al. 2003). Such threats have serious ramifi- cations for the sustainability of fish populations and entire coral reef systems (e.g. Bellwood et al. 2004, 2006, Berkes et al. 2006, Mora et al. 2006). One management option, which is widely advocated as the best conservation tool for coral reef systems, is to implement marine protected areas (MPAs; e.g. Lubchenco et al. 2003). MPAs have a demonstrated utility in promoting increases in biodiversity, organism size and biomass for a range of species (Halpern 2003). However, effective MPA establishment requires empirical data on the dispersal potential of marine organisms, and thus the connectivity of marine populations (Botsford et al. 2001, Hughes et al. 2005). Such data are lacking for nearly every reef fish species. 
Otolith chemistry has been widely employed to quantify larval dispersal and estimate population connectivity in reef fishes. As water masses vary both spatially and temporally in their chemical composition (Mann \& Lazier 2003), so will the chemistry of the otolith, with some mitigating factors (Campana 1999, Bath et al. 2000, Walther \& Thorrold 2006). Thus, otolith chemistry can provide a chemical record of the spatial life history of a fish and has been used to estimate natal homing (Thorrold et al. 2001) and larval retention (Swearer et al. 1999).

Critical for the success of this technique is an environmental mosaic of different water chemistries that allows fishes to be classified by location (Gillanders 2002). This mosaic is well established in coastal systems, where variation in water chemistry among estuaries can produce highly accurate classifications (e.g. Thorrold et al. 2001). In environments with a predominantly oceanic influence, spatial variation in elemental signatures can be reduced and some approaches, such as isotope analyses (e.g. McCulloch et al. 2005), may not be applicable, as there is little or no spatial variation in isotopic ratios. Critical to our present study was identifying spatial scales of variation in elemental chemistry that could assist in connectivity and environmental studies on the Great Barrier Reef (GBR). Environmental signals are often well recorded in carbonates, such as the aragonite of coral skeletons and the otoliths of fishes (e.g. McCulloch et al. 2003).

Despite recent work on reef systems (Swearer et al. 1999, Patterson \& Swearer 2007), including the GBR (Patterson et al. 2004a,b, 2005, Bergenius et al. 2005, Patterson \& Kingsford 2005), to our knowledge, no study has examined otolith chemistry across the continental shelf. The GBR is characterised by strong crossshelf gradients in salinity, turbidity and temperature (McCook 1996, Wolanski 2001). The physical environment of the reef ranges from the near-shore waters of low salinity, high turbidity and high temperature to the high-salinity, clear and cool waters typical of the outer shelf. It is also known that the outer shelf is periodically immersed in upwelled waters (Wolanski 2001) that could also contribute to spatial variation in aragonite chemistry.

The objective of the present study was to use a hierarchical approach and a relatively rapid liquid-based method (solution-based ICP-MS [inductively coupled plasma-mass spectrometry]) to test hypotheses relating to the otolith chemistry of Acanthochromis polyacanthus across the shelf of the central GBR, using multiple reefs within distance strata and sites within reefs. We predicted that fish from different shelf strata would vary in their otolith chemistry. This variation could then be used to examine dispersal and connectivity in reef fish populations according to clusters of reefs or even individual reefs. The findings would also provide a focus for studies that measure environmental records in aragonite using laser techniques.

Acanthochromis polyacanthus is a widespread and abundant damselfish that is sedentary and lacks a dispersive larval stage (Robertson 1973, Williams 1982). These characteristics made it an ideal model species, as elemental signatures observed in the otoliths must have been acquired from waters that had bathed the reefs where fish were collected. Specific hypotheses were as follows: (1) there would be differences in otolith signatures from fish collected among 3 distance strata (inner, mid and outer shelf) across the continental shelf that would be greater than variation within shelf strata; and (2) as the width of the continental shelf varies by latitude, some variation in otolith chemistry would be explained with absolute distance across the continental shelf. Very high concentrations of some elements were detected, and the accuracy of these data was cross-checked with another laboratory.

\section{MATERIALS AND METHODS}

Sample collections. Fish were collected from 3 replicate sites within reefs (100s of meters to kilometers apart), and 3 replicate reefs (10s of kilometers) were sampled within each of 3 distance strata (inner, mid and outer shelf), spanning the width of the continental shelf of the central GBR, Australia (Fig. 1, Table 1). Fish were collected using hand spears during September and October 2001. They were immediately stored on ice after collection before being frozen for transport back to the laboratory. Additional collections ( $\mathrm{n}=10$ fish per reef) were made at several of the reefs (Orpheus, Pandora, Havannah and Myrmidon) in October 2004 and 2005 to examine the temporal persistence of elemental patterns. All fish were $>1$ yr or older (Table 1) and were therefore adults (Munday et al. 2008).

Sample analysis. All fish were measured (standard length [SL], fork length [FL] and total length [TL] to the nearest millimeter) and weighed (to the nearest $0.01 \mathrm{~g}$ ). The largest pair of otoliths (sagittae) were removed, cleaned in Milli-Q water to remove the sagittal membrane and allowed to dry overnight. It has been well demonstrated that there are no differences in elemental chemistry between sagittae of the same fish (e.g. Rooker et al. 2001, Miller \& Shanks 2004) and therefore only 1 otolith was sampled for elements; the other sagitta was sectioned and used for aging. One otolith from each pair was selected at random and weighed using a Sartorius Genius microbalance to the nearest $0.00001 \mathrm{~g}$. The otoliths were then cleaned in $1 \% \mathrm{HNO}_{3}(65 \%$ Merck Suprapure) for 5 to $10 \mathrm{~s}$, rinsed 


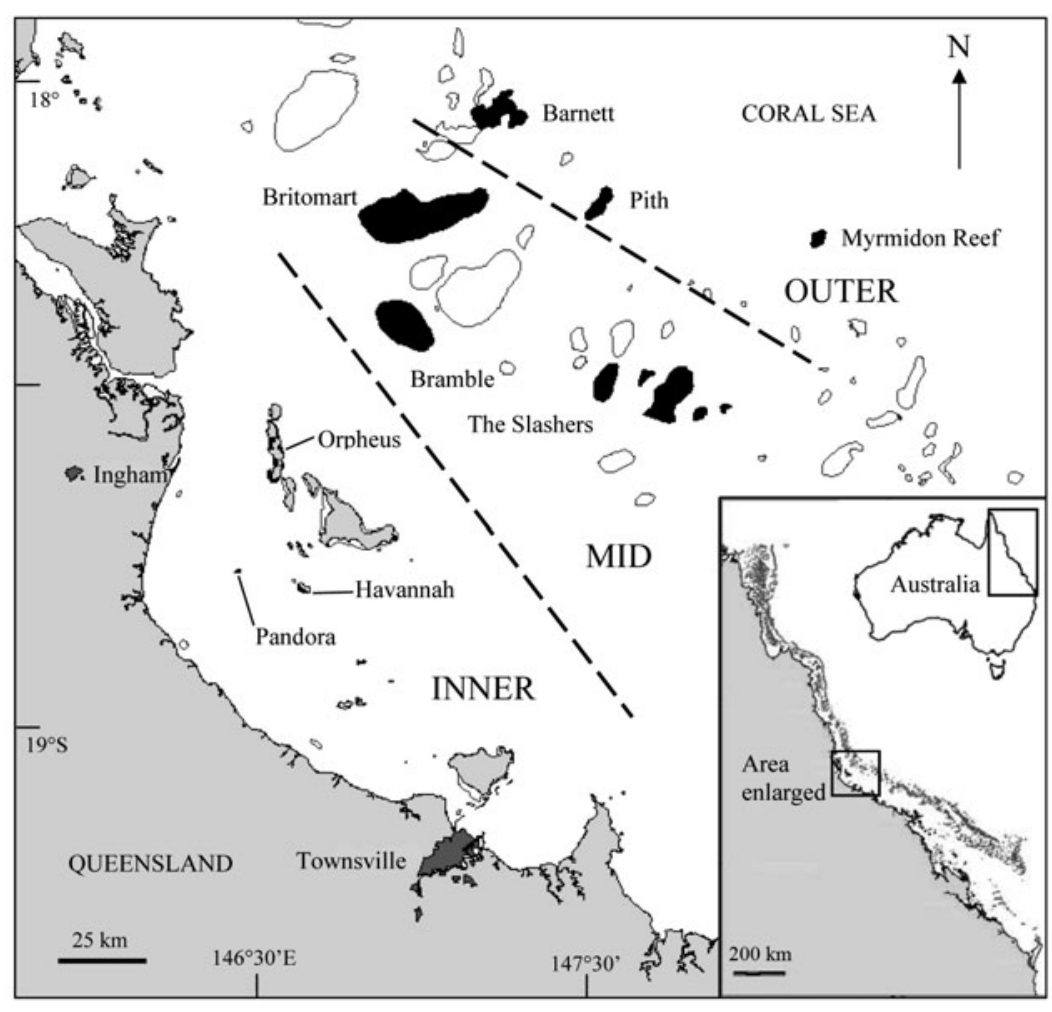

Fig. 1. Reefs in the central Great Barrier Reef where sampling was conducted. Distance strata from the mainland (inner, mid and outer shelf) are indicated. Black: reefs that were sampled; white: reefs that are submerged at high tide

made up to a final volume of $10 \mathrm{ml}$ using a dilution solution containing internal standards (10 ppb Ga and In), $\mathrm{HNO}_{3}$ and Milli-Q $\mathrm{H}_{2} \mathrm{O}$. Blank samples were prepared in the same manner, but contained no otolith and were used for blank corrections and to calculate limits of detection (LODs).

Preliminary analyses indicated that ${ }^{25} \mathrm{Mg},{ }^{43} \mathrm{Ca},{ }^{55} \mathrm{Mn},{ }^{63} \mathrm{Cu},{ }^{88} \mathrm{Sr},{ }^{111} \mathrm{Cd}$ and ${ }^{137} \mathrm{Ba}$ were detectable in the otoliths. High concentrations of ${ }^{43} \mathrm{Ca}$ and ${ }^{88} \mathrm{Sr}$ in the samples required further $(100 \times)$ dilution and separate analysis. Sample analysis was conducted using a Varian Ultra Mass 700 inductively coupled plasma-mass spectrometer (ICP-MS). Calibration solutions were prepared from a 32 element ICP-MS standard (Alpha Resources). Calibration solutions also included a matrix-matching component made from crushed, acidwashed sparid otoliths (family Sparidae) obtained from NSW Fisheries (e.g. Gillanders 2002, Patterson \& Kingsford 2005). Although not made from Acanthochromis polyacanthus otoliths, the addition of otolith material to the calibration solutions provided a robust

3 times in Milli-Q $\mathrm{H}_{2} \mathrm{O}$ and allowed to dry inside a positive flow Class-100 laminar flow cabinet (AS 1807).

Otoliths for analysis ( $\mathrm{n}=8$ fish per site) were randomly selected from the total sample and analysed in blocks of 50. Samples were dissolved in $500 \mu$ l of $\mathrm{HNO}_{3}$; the solution was then made up to a final volume of $5 \mathrm{ml}$ with Milli-Q $\mathrm{H}_{2} \mathrm{O}$. A subsample of this solution was taken (1 or $2 \mathrm{ml}$, depending on sample weight) and

Table 1. Acanthochromis polyacanthus. Collection data ( $\mathrm{n}=24$ fish per reef), including distance strata, reef, dates sampled, standard length (SL, mean \pm SE) and age (mean \pm $\mathrm{SE})$; distance from shore was measured along lines of latitude from the nearest point on the eastern coast of Australia

\begin{tabular}{|lccccc|}
\hline $\begin{array}{l}\text { Distance } \\
\text { strata }\end{array}$ & Reef & Date(s) & $\begin{array}{c}\text { SL } \\
(\mathrm{mm})\end{array}$ & $\begin{array}{c}\text { Age } \\
(\mathrm{yr})\end{array}$ & $\begin{array}{c}\text { Distance } \\
\text { from shore } \\
(\mathrm{km})\end{array}$ \\
\hline Inner shelf & Pandora Reef & 3 Sep 2001 & $85.21 \pm 1.40$ & $5.17 \pm 0.35$ & 16 \\
& Havannah Island & 3 \& 4 Sep 2001 & $77.54 \pm 0.84$ & $4.29 \pm 0.41$ & 29 \\
& Orpheus Island & 4 \& 5 Sep 2001 & $83.38 \pm 1.01$ & $4.29 \pm 0.32$ & 16 \\
Mid shelf & Bramble Reef & 15 Oct 2001 & $90.00 \pm 0.69$ & $4.33 \pm 0.35$ & 43 \\
& Britomart Reef & 16 Oct 2001 & $94.88 \pm 0.81$ & $5.21 \pm 0.30$ & 41 \\
& The Slashers & 20 Oct 2001 & $103.25 \pm 1.79$ & $4.38 \pm 0.47$ & 97 \\
Outer shelf & Barnett Patches & 17 Oct 2001 & $99.33 \pm 1.28$ & $4.75 \pm 0.44$ & 88 \\
& Pith Reef & 18 Oct 2001 & $99.13 \pm 1.35$ & $4.83 \pm 0.41$ & 84 \\
& Myrmidon Reef & 19 Oct 2001 & $100.88 \pm 1.16$ & $4.54 \pm 0.49$ & 124 \\
\hline
\end{tabular}
method of tracking signal drift, and standard addition calibration is a common technique for samples with a heavy matrix.

LODs were calculated from the concentration of analyte yielding a signal equivalent to 3 times the standard deviation $(3 \sigma)$ of the blank signal for each of the elements analysed (in ppb): ${ }^{25} \mathrm{Mg}(1.02),{ }^{43} \mathrm{Ca}(41)$, ${ }^{55} \mathrm{Mn}(0.086),{ }^{63} \mathrm{Cu}(0.007),{ }^{88} \mathrm{Sr}(0.074),{ }^{111} \mathrm{Cd}(0.76)$ and ${ }^{137} \mathrm{Ba}$ (0.012). Analyses were terminated and the instrument recalibrated if recovery of the internal standards (Ga and In) fell outside $30 \%$ of their initial values, implying excessive instrument drift. Relative standard deviation (RSD) was used as an estimate of instrument precision for each element, and values were considered unreliable if variation in replicate measurements $(\mathrm{n}=3)$ within otolith samples exceeded $10 \%$. $\mathrm{Cd}$ values were usually below the calculated LODs and were therefore discarded from further analysis. The values ob- 
tained for Mg were also regarded as unreliable due to high variability among all samples and were also discarded.

Statistical analyses. Elemental concentrations were converted to molar concentrations and expressed as a ratio to $\mathrm{Ca}$ as the elements are considered to substitute for calcium within the crystalline lattice of the otolith. Linear regression determined that otolith weight was positively correlated with fish length for fish from all distance strata $\left(\mathrm{r}^{2}=0.74, \mathrm{n}=216\right)$. The relationship between age and otolith weight was also positive and significant using analysis of variance (ANOVA: $F_{1,214}=$ 134, $\mathrm{p}<0.001 ; \mathrm{r}^{2}=0.387$ ), and, therefore, otolith weight is a proxy for age. A similar age range of fish was sampled at each reef (Table 1), and ANOVA demonstrated that there were no significant differences in age at the levels of distance strata $\left(F_{2,6}=0.07\right.$, $\mathrm{p}>0.05)$, reefs nested within each distance stratum $\left(F_{6,18}=0.97, \mathrm{p}>0.05\right)$ and sites nested within reefs $\left(F_{18,189}=1.14, \mathrm{p}>0.05\right)$. Correlations were done at each distance stratum to determine if otolith weight and elemental concentration were related. Significant relationships existed only for Sr. We adjusted for these relationships by multiplying the otolith weight by the slope of the regression and subtracting this value from the elemental concentrations (Gillanders 2002). All analyses of Sr were carried out using this corrected data (the results of which we note differed little from analyses using uncorrected Sr data).

Spatial variation was examined using a fully nested 3-factor (distance strata, reefs within distance strata, and sites within reefs within distance strata) ANOVA for each element, and variance components were calculated for each factor; all factors were treated as random. Pearson's correlations were used to test the relationship between elemental ratios and distance from shore. An additional orthogonal ANOVA, including the factors of year and reef, both treated as random factors, was used to test the consistency of Ba/Ca concentrations at several reefs (Myrmidon, Orpheus, Pandora and Havannah) over several years (2001, 2004 and 2005). The assumption of homogeneity of variance was tested prior to analysis using Cochran's $C$-test, and ANOVAs were conducted on non-transformed data. All analyses were carried out using SYSTAT Ver. 10.

Data were $\ln (x+1)$ transformed prior to multivariate analysis to reduce heterogeneity of the within-group variance-covariance matrices (Quinn \& Keough 2002). Multi-element signatures were analysed by multivariate analysis of variance (MANOVA) using the same design as for the univariate ANOVAs, but including all elements. We used Pillai's trace as the test statistic, as it is robust to deviations from multivariate normality (Quinn \& Keough 2002). Quadratic discriminant function analysis (DFA) was used to determine the ability of cross-shelf elemental signatures to correctly assign a fish to a reef on the inner, mid, or outer shelf, as well as to reefs within a shelf and sites within a reef. Fish were classified using a jackknife method. Similar methods were used to examine the separation of otoliths by shelf position and reef over time.

Inter-laboratory comparison. After analysing the data it was apparent that the values for $\mathrm{Ba} / \mathrm{Ca}$ in fish from different sites were falling out into groups of low, medium and very high. We wanted, therefore, to verify our findings for $\mathrm{Ba}$, an important element in otolith studies. We randomly chose sample groups consisting of 5 otoliths from sites that corresponded to the 3 concentration groups identified (low: $\mathrm{Ba} / \mathrm{Ca} \leq 20 \mu \mathrm{mol}$ $\mathrm{mol}^{-1}$; medium: Ba/Ca ca. 20 to $40 \mu \mathrm{mol} \mathrm{mol}{ }^{-1}$; high: $\mathrm{Ba} / \mathrm{Ca}>40 \mu \mathrm{mol} \mathrm{mol}{ }^{-1}$ ) and analysed the chemistry of the otoliths in 2 laboratories (our laboratory at James Cook University and one at the University of Ghent, Belgium). The laboratory in Ghent was given coded samples only, and did not know the concentration grouping or the collection location of the samples.

Samples in Belgium were prepared as noted above for Australia and in an identical manner. Sample analyses $\left({ }^{137} \mathrm{Ba}\right.$ and $\left.{ }^{43} \mathrm{Ca}\right)$ were conducted using a Perkin Elmer Sciex Elan 5000 ICP-MS in Belgium, and standard solutions were prepared from commercially available $10 \mathrm{mg} \mathrm{l}^{-1}$ multi-element standards by appropriate dilution with $1 \% \mathrm{HNO}_{3}$ Suprapure $65 \% \mathrm{HNO}_{3}$ (Merck). The dilution factors used in both laboratories were the same, and all other analytical procedures used in the laboratory in Belgium were the same as noted above. For the laboratory comparison, an ANOVA was used with the fixed factors of laboratory and concentration group to test for differences. If there were differences between laboratories we expected a significant laboratory $\times$ concentration group interaction.

\section{RESULTS}

\section{Cross-shelf comparisons}

There were no consistent patterns of elemental ratios among distance strata across the shelf. Despite strong trends for differences among reefs within distance strata (e.g. Ba/Ca for the outer shelf, Myrmidon Reef), there were no significant differences. Great differences, however, were found for all elemental ratios among sites within reefs (Table 2, Fig. 2). Variance components indicated that sites within reefs accounted for most of the variation in $\mathrm{Cu} / \mathrm{Ca}$ and $\mathrm{Sr} / \mathrm{Ca}$ (80 to $85 \%$ ); for $\mathrm{Mn} / \mathrm{Ca}$ most of the variation was at the residual level. Variation in $\mathrm{Ba} / \mathrm{Ca}$ ratios was explained by differences between reefs and sites within reefs. 
Table 2. ANOVA for elemental ratios. ${ }^{*} \mathrm{p}<0.05_{;}{ }^{* *} \mathrm{p}<0.01 ; \%$ : variance components for each factor expressed as a percentage of the total variation

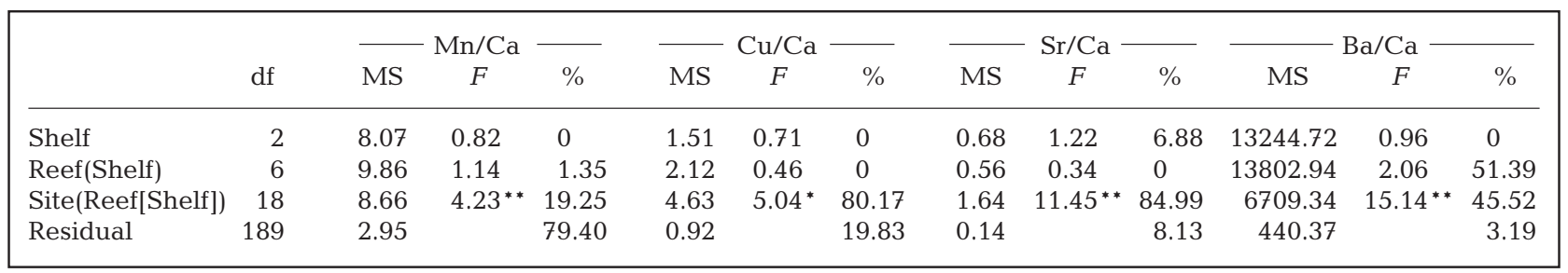

There were significant relationships with absolute distance from shore for some elements (Fig. 3). There was a positive relationship between distance from shore and $\mathrm{Cu} / \mathrm{Ca}$, Sr/Ca and $\mathrm{Ba} / \mathrm{Ca}$. There was no sig- nificant relationship for Mn/Ca (Fig. 3, Pearson's correlations on mean values for all sites $-\mathrm{Mn}$ : 0.017; p > 0.05; Cu: 0.364; p < 0.05; Sr: 0.419; p < 0.05; Ba: 0.651; $\mathrm{p}<0.01)$. Residual variation was largely due to varia-
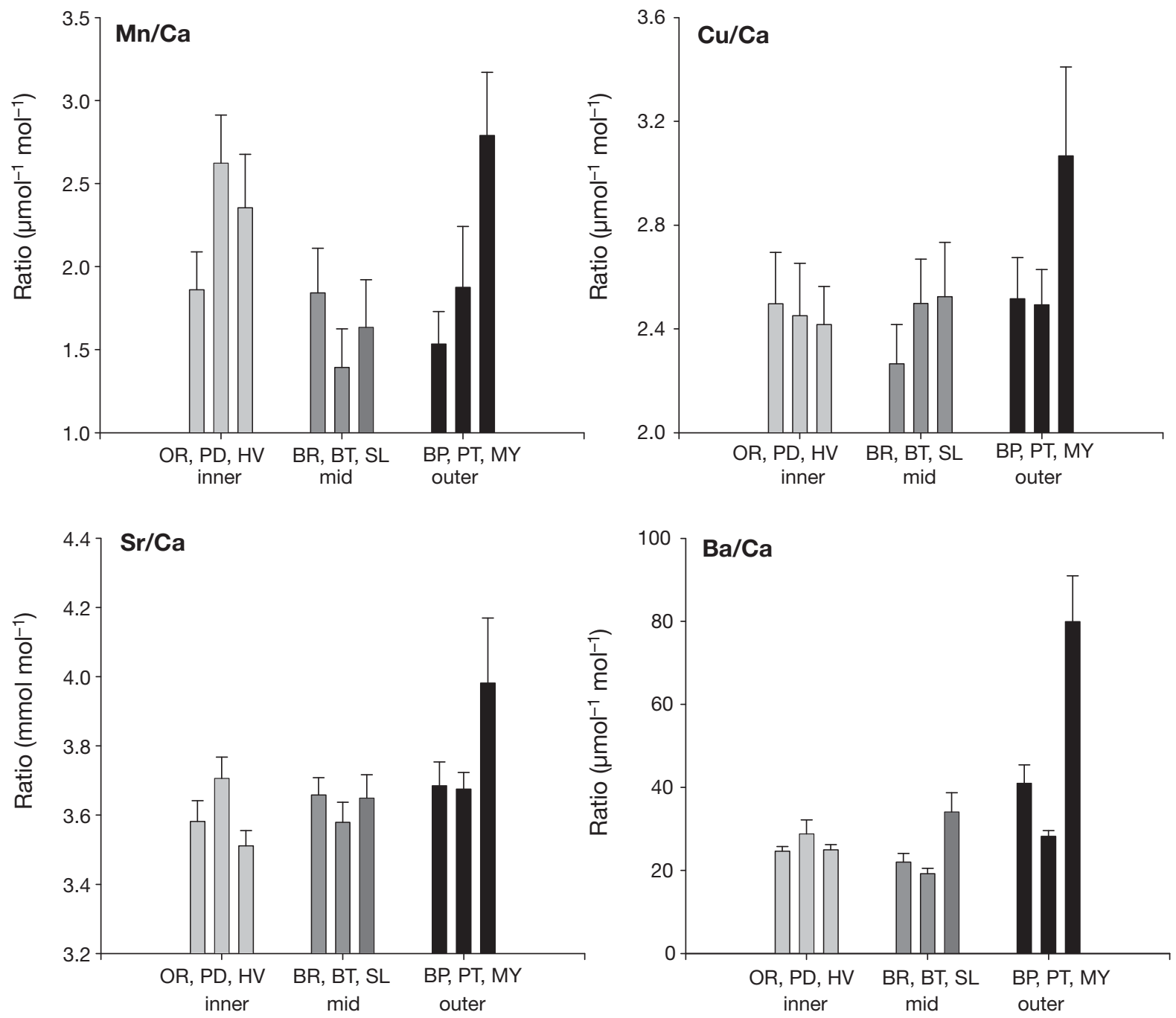

Distance strata

Fig. 2. Acanthochromis polyacanthus. Elemental ratios in $\mu \mathrm{mol} \mathrm{mol}{ }^{-1}$ (or mmol mol ${ }^{-1}$ for Sr/Ca) + standard error for otoliths. Ratios are given by distance strata and 3 reefs within each stratum, the mean for each reef is based on 3 separate sites (n = 8 fish). OR: Orpheus; PD: Pandora; HV: Havannah; BR: Bramble; BT: Britomart; SL: The Slashers; BP: Barnett Patches; 

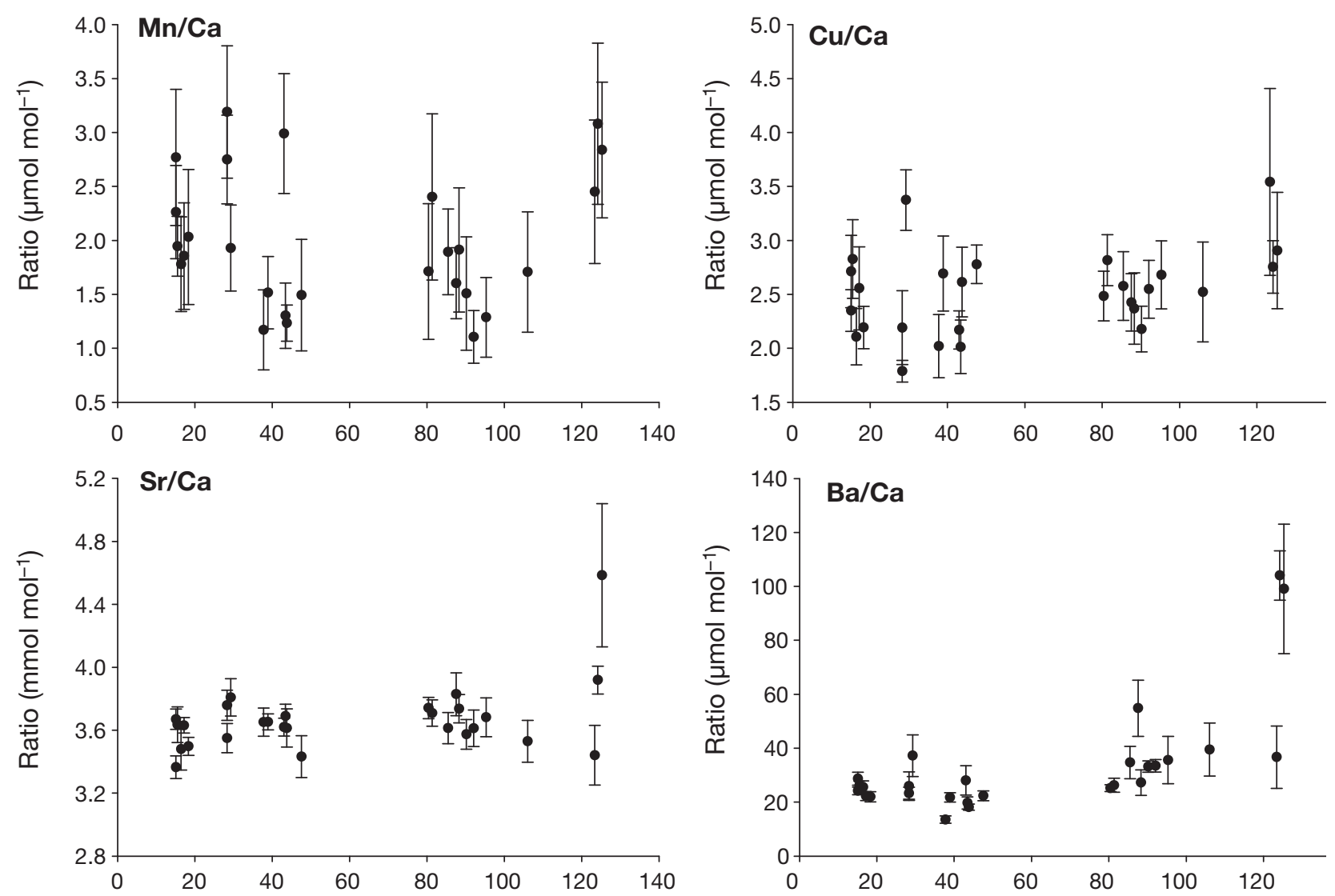

Distance from shore $(\mathrm{km})$

Fig. 3. Acanthochromis polyacanthus. Elemental ratios in $\mu \mathrm{mol} \mathrm{mol}{ }^{-1}$ (or $\mathrm{mmol} \mathrm{mol}^{-1}$ for Sr/Ca) + standard error for otoliths. Ratios are given for all sites (sites $=27$ ) at multiple reefs at different distances from shore (see Table 1 for average distance by reef); the mean for each site is based on $n=8$ fish

tion among sites. High values at Myrmidon Reef dominated these relationships; for this reason, analyses were repeated without the sites at this reef. The relationship was still positive for $\mathrm{Sr} / \mathrm{Ca}$ and $\mathrm{Ba} / \mathrm{Ca}$, while $\mathrm{Cu} / \mathrm{Ca}$ was not significant $(\mathrm{n}=24$; Ba: 0.559; $\mathrm{p}<0.01$; $\mathrm{Cu}: 0.096 ; \mathrm{p}>0.05 ; \mathrm{Sr}: 0.270 ; \mathrm{p}>0.05)$. The removal of Myrmidon Reef resulted in a negative relationship with distance for $\mathrm{Mn} / \mathrm{Ca}$; the highest ratios were found near the mainland (Mn: $-0.387 ; \mathrm{p}<0.05$ ).

A DFA indicated there was a significant separation in multi-element signatures by shelf position ( $\mathrm{n}=72$; Pillai's trace, $F_{9,422}=7.66, \mathrm{p}<0.001$; Fig. 4 ), although the classification accuracies were generally low with only 42,53 and $65 \%$ of the fish correctly classified to inner, mid and outer shelf, respectively. DFAs of reefs across the shelf indicated significant separation in both the inner and mid shelf reefs, but not in outer shelf reefs (Table 3), with classification accuracies similar to those determined for shelf position, ranging from 29 to $67 \%$. Classification accuracies were the highest for sites within reefs, ranging from 38 to $88 \%$. Myrmidon
Reef had the highest classification accuracies, ranging from 75 to $88 \%$ for the 3 sites, largely due to high values of $\mathrm{Cu} / \mathrm{Ca}$ and $\mathrm{Ba} / \mathrm{Ca}$.

Significant differences in $\mathrm{Ba} / \mathrm{Ca}$ were found among reefs, and these results were consistent among years, largely due to high $\mathrm{Ba}$ ratios at Myrmidon Reef (ANOVA: reef: $F_{3,108}=118.835, \mathrm{p}<0.001$; year: $F_{2,6}=$ $0.124, \mathrm{p}>0.05$; reef $\times$ year: $\left.F_{6,108}=0.852, \mathrm{p}>0.05\right)$. A DFA by shelf position using just $\mathrm{Ba} / \mathrm{Ca}$ indicated that 93 and $98 \%$ of the outer and inner shelf otoliths, respectively, collected from all years ( $\mathrm{n}=10$ otoliths reef $^{-1} \mathrm{yr}^{-1}$ ) were classified correctly (Fig. 5; Pillai's trace, $\left.F_{1,188}=309.846, \mathrm{p}<0.001\right)$. Classification accuracies by individual reef were not high, with the exception of Myrmidon Reef, with 13, 20,63 and $90 \%$ of the otoliths from Pandora, Orpheus, Havannah and Myrmidon, respectively, classified correctly (Pillai's trace, $\left.F_{3,116}=102.264, \mathrm{p}<0.001\right)$. DFA scores from outer reefs that overlapped with inner reefs were from a sheltered lagoonal site at Myrmidon Reef, where exposure to upwelling was low. 


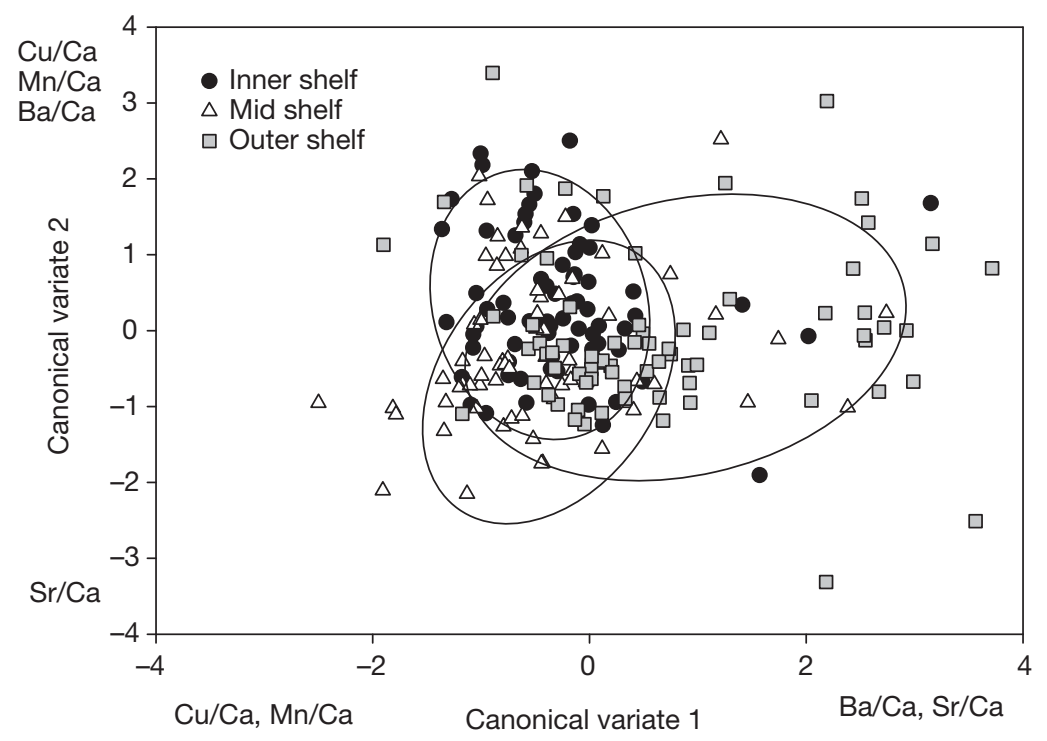

Fig. 4. Acanthochromis polyacanthus. Plot of fish by distance strata using canonical variates derived from the quadratic discriminant function analysis. Ellipses indicate $95 \%$ confidence levels. Elemental ratios on axes indicate positive or negative loadings

Table 3. Results of the jackknife cross validation classification procedures from different reefs within shelf position $(\mathrm{n}=24$; $\mathrm{df}=8,134)$, with the percent correct and sites within reefs $(\mathrm{n}=8 ; \mathrm{df}=8,38)$. Results are given as a percentage of the total number classified correctly. ${ }^{*} \mathrm{p}<0.05 ;{ }^{* *} \mathrm{p}<0.01$

\begin{tabular}{|c|c|c|c|c|c|c|c|}
\hline \multirow{2}{*}{$\begin{array}{l}\text { Distance } \\
\text { strata } \\
\text { Inner shelf }\end{array}$} & \multirow{2}{*}{$\begin{array}{l}\text { Reef } \\
\text { Pandora } \\
\text { Havannah } \\
\text { Orpheus }\end{array}$} & \multicolumn{2}{|c|}{$\begin{array}{c}\text { Reefs within shelf } \\
\% \quad F \\
\text { correct }\end{array}$} & $\begin{array}{c}\begin{array}{c}\text { Site } 1 \\
(\%)\end{array} \\
63\end{array}$ & \multicolumn{2}{|c|}{$\begin{array}{c}\text { Sites within reefs } \\
\text { Site } 2 \quad \text { Site } 3 \\
(\%) \\
(\%)\end{array}$} & $F$ \\
\hline & & $\begin{array}{l}54 \\
67 \\
63\end{array}$ & $3.73^{* *}$ & $\begin{array}{l}63 \\
63 \\
38\end{array}$ & $\begin{array}{l}50 \\
75 \\
75\end{array}$ & $\begin{array}{l}50 \\
50 \\
50\end{array}$ & $\begin{array}{l}0.95 \\
2.28^{*} \\
1.89\end{array}$ \\
\hline Mid shelf & $\begin{array}{l}\text { Bramble } \\
\text { Britomart } \\
\text { Slashers }\end{array}$ & $\begin{array}{l}50 \\
46 \\
25\end{array}$ & $2.25^{*}$ & $\begin{array}{l}75 \\
75 \\
75\end{array}$ & $\begin{array}{l}50 \\
75 \\
63\end{array}$ & $\begin{array}{l}75 \\
75 \\
63\end{array}$ & $\begin{array}{l}2.32^{*} \\
2.89^{*} \\
0.54\end{array}$ \\
\hline Outer shelf & $\begin{array}{l}\text { Barnett } \\
\text { Pith } \\
\text { Myrmidon }\end{array}$ & $\begin{array}{l}46 \\
29 \\
55\end{array}$ & 1.49 & $\begin{array}{l}63 \\
63 \\
75\end{array}$ & $\begin{array}{l}50 \\
63 \\
88\end{array}$ & $\begin{array}{l}75 \\
63 \\
88\end{array}$ & $\begin{array}{l}0.68 \\
2.40^{*} \\
3.60^{* *}\end{array}$ \\
\hline
\end{tabular}

\section{Inter-laboratory comparison}

Mean $\mathrm{Ba} / \mathrm{Ca}$ ratios measured were similar between laboratories for low, medium and high concentration groups (Fig. 6). Both laboratories measured a

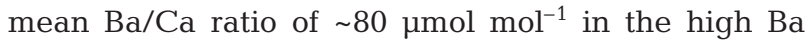
group, and some replicates were $>100 \mu \mathrm{mol} \mathrm{mol}{ }^{-1}$. The ANOVA indicated that there were significant differences in $\mathrm{Ba} / \mathrm{Ca}$ by concentration group (Table 4); there was no significant laboratory effect that would also indicate differences between laboratories. We are confident, therefore, that our results are accurate.

\section{DISCUSSION}

Elemental signatures varied little with shelf position. This result was surprising given the strong environmental gradients found across the shelf in our study area, as differences in otolith chemistry have commonly been found over much smaller spatial scales along coastlines. For example, several studies have indicated that riverine or lagoonal plumes can influence otolith Ba concentrations (Kingsford \& Gillanders 2000, Patterson et al. 2004a), as well as coral chemistry (McCulloch et al. 2003). However, it appears that these gradients were not strong enough across the shelf to produce significant differences when averaged over the life of fish (up to $12 \mathrm{yr}$ for Acanthochromis polyacanthus; Kingsford \& Hughes 2005).

There were significant linear relationships with actual distance from shore as opposed to shelf position. This trend was particularly clear for $\mathrm{Sr} / \mathrm{Ca}$, which increased with distance from shore. $\mathrm{Sr} / \mathrm{Ca}$ was also the only elemental ratio for which shelf position accounted for some of the variation noted, albeit a small amount (6.9\%). This pattern was likely related to a freshwater influence near shore. Evaporation can also influence salinity and otolith Sr concentrations (Martin \& Wuenschel 2006), although inner shelf reefs are often exposed to warmer waters and therefore higher evaporation than outer shelf reefs (Wolanski 2001), which would tend to elevate the Sr. Otolith Sr/Ca ratios are also known to be influenced by temperature (e.g. Bath et al. 2000), although the relationship is not necessarily straightforward (Elsdon \& Gillanders 2002). Cu/Ca varied little by shelf position, but peaked noticeably at Myrmidon Reef. Several studies have linked increased $\mathrm{Cu}$ levels to upwelling (Boyle et al. 1981, Jones \& Murray 1984). As will be discussed below, Myrmidon Reef is an area of known upwelling, and this oceanographic feature likely contributed to the elevated $\mathrm{Cu}$ levels noted at this location. Similarly, Mn/Ca was high on the inner shelf reefs and highest at Myrmidon Reef, with low levels at the mid shelf range. This pattern is more difficult to explain, but could potentially be related to riverine input near shore and upwelling at Myrmidon Reef (Jones \& Murray 1985). 


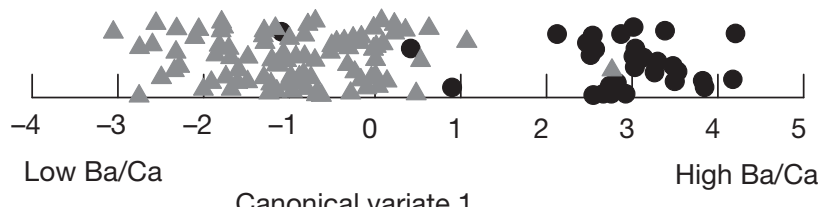

Canonical variate 1

Fig. 5. Acanthochromis polyacanthus. Jittered dot density plot of otoliths collected over $3 \mathrm{yr}(2001,2004,2005)$ from the outer $(\mathrm{n}=30 ; \bullet)$ and inner shelf $(\mathrm{n}=90 ; \boldsymbol{\Delta})$ of the Great Barrier Reef and the canonical variate of the $\mathrm{Ba} / \mathrm{Ca}$ ratios

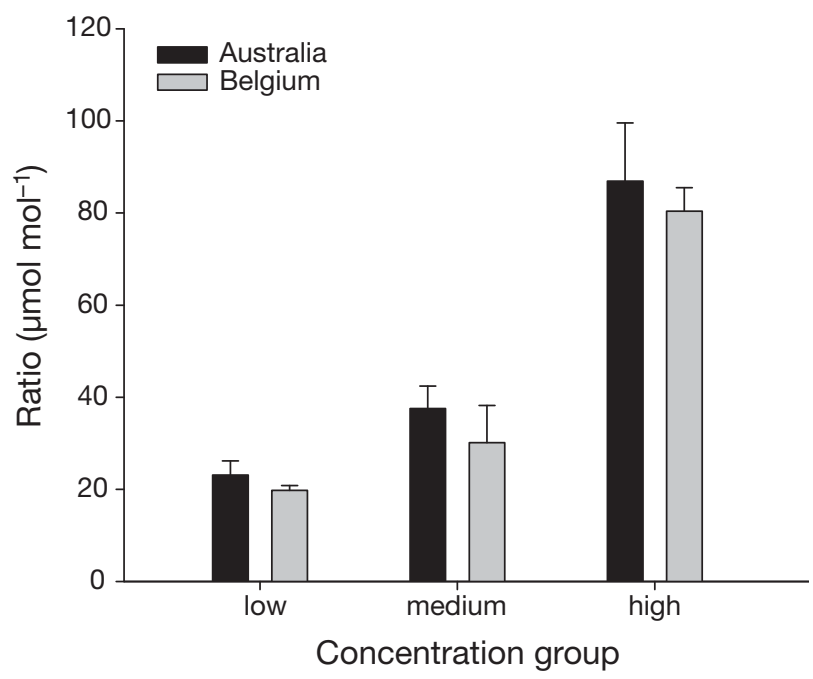

Fig. 6. Ba/Ca ratios (+SE) reported from the 2 laboratories for the 3 concentration groups ( $\mathrm{n}=5$ per laboratory per concentration group)

Table 4. ANOVA results for otolith $\mathrm{Ba} / \mathrm{Ca}$ concentration groups (low, medium, high) as determined by 2 laboratories (n = 5 laboratory ${ }^{-1}$ concentration group $\left.{ }^{-1}\right) .{ }^{* *} \mathrm{p}<0.001$

\begin{tabular}{|lrrc|}
\hline Source & \multicolumn{3}{c|}{ Ba/Ca } \\
& df & \multicolumn{1}{c|}{ MS } & \multicolumn{1}{c|}{$F$} \\
\hline Laboratory & 1 & 247.78 & 1.04 \\
Concentration group & 2 & 10825.52 & $835.75^{* *}$ \\
Laboratory $\times$ concentration group & 2 & 12.95 & 0.055 \\
Residual & 24 & 237.42 & \\
\hline
\end{tabular}

There was great variation at the level of sites within reefs for all elements and, in some cases, within distance strata. The most noticeable trend in the data was the striking difference in the $\mathrm{Ba} / \mathrm{Ca}$ ratios of otoliths from Myrmidon Reef and all the other reefs sampled; the difference was strongest between Myrmidon Reef and inshore reefs. Indeed, the mean $\mathrm{Ba} / \mathrm{Ca}$ ratio at Myrmidon Reef was more than twice the ratio measured for inshore reefs, with some values being the highest levels ever measured in marine fish otoliths; these results were confirmed in our paired laboratory tests.
Myrmidon Reef is the outermost reef from the mainland in our study area and is at the edge of the continental shelf. The reef is subjected to persistent upwelling via internal tides and wind effects (Wolanski \& Pickard 1983). Upwelled waters are known to be enriched in trace elements (e.g. $\mathrm{Ba}, \mathrm{Cu}, \mathrm{Cd}$ ), which can then be incorporated into calcified structures such as corals (e.g. Lea et al. 1989) and, as otolith chemistry is primarily the product of water chemistry (Campana 1999, Bath et al. 2000, Walther \& Thorrold 2006), likely otoliths (Patterson et al. 1999, 2004a,b, Patterson \& Kingsford 2005). This influence of upwelling was also persistent over $3 \mathrm{yr}$ among reefs, with otoliths from Myrmidon Reef consistently and distinctly higher in $\mathrm{Ba} / \mathrm{Ca}$ than those from inshore reefs.

Despite the strong upwelling signature at Myrmidon Reef, it was difficult to discriminate among individual reefs within a group or distance stratum using otolith chemistry. This is likely because reefs in close proximity are sharing water masses and thus do not have discrete elemental signatures. In addition, the lack of a robust reef signature may be due to localised upwelling of different chemistry that only affects parts of reefs and lagoonal waters and thus introduces further variance (Kingsford et al. 2008). A similar conclusion was reached by Patterson \& Kingsford (2005) and Patterson et al. (2004b), who sampled juvenile reef fish otoliths, including Acanthochromis polyacanthus, from reefs of both the northern and southern GBR and were unable to detect convincing differences in otolith chemistry at intermediate spatial scales. In contrast, Bergenius et al. (2005) found differences in the otolith chemistry of the serranid Plectropomus leopardus from reefs within regions of the GBR, although they used adult fish that may have migrated from different reefs or regions. Moreover, no measure of variation at the level of site was used in their study.

There was significant variation in the individual otolith chemistry of Acanthochromis polyacanthus at the level of sites for each element, and site had higher classification accuracies than either shelf position or reef. Variation in the otolith chemistry of reef fishes has previously been detected on small spatial scales in coral reef systems. For example, Patterson \& Kingsford (2005) found significant variation in the otolith chemistry of $A$. polyacanthus collected from different sites within a reef (100s of meters), as well as broods within each site (1 to $10 \mathrm{~m}$ ). Lo-Yat et al. (2005) also found differences among sites separated by $200 \mathrm{~m}$ in French Polynesia. The classification accuracies in our study were highest for the sites at Myrmidon Reef. Given the oceanography of this reef, it seems likely that the high classification accuracies were again generated by upwelling, as 1 site was on the lagoonal side of the reef and had lower Ba/Ca levels (Site 1; Table 3), while 
2 sites were located on the ocean side of the reef where exposure to cool, high-density, upwelled waters was greatest.

Our research using whole otoliths indicates that many reefs are unlikely to have a unique water chemistry for the whole reef. This has also been found in studies using laser ablation ICP-MS (LA-ICP-MS; Patterson et al. 2004a) and poses a problem for connectivity studies. Our approach has identified areas where more detailed studies could be conducted on larval sources with distinct chemistries (e.g. Myrmidon Reef), perhaps augmented by batch tagging (e.g. Almany et al. 2007). Combining natural signatures with artificially induced signatures may prove to be a robust strategy for investigating larval dispersal and population connectivity.

Solution-based analyses are of high utility for identifying robust spatial patterns of elemental variation in otoliths, because large numbers of otoliths can be assayed faster than with LA-ICP-MS. LA-ICP-MS has greater chronological resolution of differences within individuals, but all otoliths must be sectioned and multiple elemental counts related to the position of annual or daily increments. Liquid-based analyses, therefore, combine well with an LA-ICP-MS approach for more focused studies, be they on connectivity or on environmental variation.

In conclusion, the present study is the first to examine otolith chemistry across the continental shelf of the GBR. Given the significant results of previous studies on otolith chemistry at similar spatial scales along the coast, combined with the strong gradients known to occur across the shelf, our largely non-significant cross-shelf results were surprising. In general, we found that variation in otolith chemistry was greater on smaller spatial scales than on larger spatial scales. The lack of robust reef-wide elemental signatures is problematic for connectivity studies that use natural tags (e.g. Swearer et al. 1999). However, otolith chemistry can be a useful discriminator on smaller spatial scales, and particularly in areas of unique or distinctive chemistries (e.g. with upwelling or discrete lagoonal waters). MPA designs, for example, may be able to incorporate areas of distinct chemistry into their boundaries to facilitate tracking of larval dispersal and connectivity, at least in some instances. Now that we have identified large elemental anomalies, highresolution analyses with LA-ICP-MS could provide records of the frequency of events such as upwelling. Future studies may further elucidate the utility of otoliths to act as environmental recorders.

Acknowledgements. We thank D. Welch, M. O'Callaghan and the crews of the RV 'Orpheus', the MV 'Hero' and the MV 'Escape' for assistance with collections. Y. Hu assisted with the solution-based analyses in Australia, and analyses in Belgium were conducted by F. Vanhaecke at the University of Ghent. Comments by B. Curley and B. Walther improved an earlier draft of the manuscript. This project was partly funded by an ARC grant to M.J.K.

\section{LITERATURE CITED}

Almany GR, Berumen ML, Thorrold SR, Planes S, Jones GP (2007) Local replenishment of coral reef fish populations in a marine reserve. Science 316:742-744

Bath GE, Thorrold SR, Jones CM, Campana SE, McLaren JW, Lam JWH (2000) Strontium and barium uptake in aragonite otoliths of marine fish. Geochim Cosmochim Acta 64:1705-1714

Bellwood DR, Hughes TP, Folke C, Nystrom M (2004) Confronting the coral reef crisis. Nature 429:827-833

Bellwood DR, Hoey AS, Ackerman JL, Depczynski M (2006) Coral bleaching, reef fish community phase shifts and the resilience of coral reefs. Glob Change Biol 12: 1587-1594

> Bergenius MAJ, Mapstone BD, Begg GA, Murchie CD (2005) The use of otolith chemistry to determine stock structure of three epinephaline serranid coral reef fishes on the Great Barrier Reef, Australia. Fish Res 72:253-270

> Berkes F, Hughes TP, Steneck RS, Wilson JA and others (2006) Globalization, roving bandits and marine resources. Science 311:1557-1558

Botsford LW, Hastings A, Gaines SD (2001) Dependence of sustainability on the configuration of marine reserves and larval dispersal distance. Ecol Lett 4:144-150

Boyle EA, Huested SS, Jones SP (1981) On the distribution of copper, nickel and cadmium in the surface waters of the North Atlantic and North Pacific Oceans. J Geophys Res 86:8048-8066

Campana SE (1999) Chemistry and composition of fish otoliths: pathways, mechanisms and applications. Mar Ecol Prog Ser 188:263-297

Elsdon TS, Gillanders BM (2002) Interactive effects of temperature and salinity on otolith chemistry: challenges for determining environmental histories of fish. Can J Fish Aquat Sci 59:1796-1808

Gardner TA, Côte IM, Gill JA, Grant A, Watkinson AR (2003) Long-term region-wide declines in Caribbean corals. Science 301:958-960

Gillanders BM (2002) Temporal and spatial variability in elemental composition of otoliths: implications for determining stock identity and connectivity of populations. Can J Fish Aquat Sci 59:669-679

Halpern BS (2003) The impact of marine reserves: Do reserves work and does size matter? Ecol Appl 13:117-137

- Harvell CD, Mitchell JR, Altizer S, Dobson AP, Ostfeld RS, Samuel MD (2002) Climate warming and disease risk for terrestrial and marine biota. Science 296:2158-2162

Hughes TP, Baird AH, Bellwood DR, Card M and others (2003) Climate change, human impacts, and the resilience of coral reefs. Science 301:929-933

> Hughes TP, Bellwood DR, Folke C, Steneck RS, Wilson J (2005) New paradigms for supporting the resilience of marine ecosystems. Trends Ecol Evol 20:380-386

> Jackson JBC, Kirby MX, Berger WH, Bjorndal KA and others (2001) Historical overfishing and the recent collapse of coastal ecosystems. Science 293:629-638

Jones CJ, Murray JW (1984) Nickel, cadmium and copper in the Northeast Pacific off the coast of Washington. Limnol Oceanogr 29:711-720 
Jones CJ, Murray JW (1985) The geochemistry of manganese in the northeast Pacific Ocean off Washington. Limnol Oceanogr 30:81-92

Kingsford MJ, Gillanders BM (2000) Variation in concentrations of trace elements in the otoliths and eye lenses of a temperate reef fish, Parma microlepis, as a function of depth, spatial scale and age. Mar Biol 137:403-414

Kingsford MJ, Hughes JM (2005) Patterns of growth, mortality, and size of the tropical damselfish Acanthochromis polyacanthus across the continental shelf of the Great Barrier Reef. Fish Bull (Wash DC) 103:561-573

Kingsford MJ, Patterson HM, Flood MJ (2008) The influence of elemental chemistry on the widths of otolith increments in the neon damselfish (Pomacentrus coelestis). Fish Bull (Wash D C) 106:135-142

Lea DW, Shen GT, Boyle EA (1989) Coralline barium records temporal variability in equatorial Pacific upwelling. Nature 340:373-376

Lo-Yat A, Meekin M, Munksgaard N, Parry D, Planes S, Wolter M, Carleton J (2005) Small-scale spatial variation in the elemental composition of otoliths of Stegastes nigricans (Pomacentridae) in French Polynesia. Coral Reefs 24: 646-653

Lubchenco J, Palumbi SR, Gaines SD, Andelman S (2003) Plugging a hole in the ocean: the emerging science of marine reserves. Ecol Appl 13:3-7

Mann KH, Lazier JRN (2003) Dynamics of marine ecosystems: biological-physical interactions in the oceans. Blackwell Science, Oxford

Martin GB, Wuenschel MJ (2006) Effect of temperature and salinity on otolith element incorporation in juvenile gray snapper Lutjanus griseus. Mar Ecol Prog Ser 324: 229-239

McCook LJ (1996) Effects of herbivores and water quality on Sargassum distribution on the central Great Barrier Reef: cross-shelf transplants. Mar Ecol Prog Ser 139:179-192

McCulloch M, Fallon SJ, Wyndham T, Hendy EJ, Lough JM, Barnes DJ (2003) Coral record of increased sediment flux to the inner Great Barrier Reef of Australia since European settlement. Nature 421:727-730

> McCulloch M, Cappo M, Aumend J, Müller W (2005) Tracing the life history of individual barramundi using laser ablation MC-ICP-MS Sr-isotopic and Sr/Ba ratios in otoliths. Mar Freshw Res 56:637-644

Miller JS, Shanks AL (2004) Evidence for limited larval dispersal in black rockfish (Sebastes melanops): implications for population structure and marine-reserve design. Can J Fish Aquat Sci 61:1723-1735

Mora C, Andrefouet S, Costello MJ, Kronenburg C and others (2006) Coral reefs and the global network of marine protected areas. Science 312:1750-1751

Munday PL, Jones GP (1998) The ecological implications of small body size among coral-reef fishes. Oceanogr Mar Biol Annu Rev 36:373-412

Munday PL, Kingsford MJ, O'Callaghan M, Donelson JM (2008) Elevated temperature restricts growth potential of

Editorial responsibility: Otto Kinne, Oldendorf/Luhe, Germany the coral reef fish Acanthochromis polyacanthus. Coral Reefs 27:927-931

Myers RA, Worm B (2003) Rapid depletion of predatory fish communities. Nature 423:280-283

Pandolfi JM, Bradbury RH, Sala E, Hughes TP and others (2003) Global trajectories of the long-term decline of coral reef ecosystems. Science 301:955-958

Patterson HM, Kingsford MJ (2005) Elemental signatures of Acanthochromis polyacanthus otoliths from the Great Barrier Reef have significant temporal, spatial and betweenbrood variation. Coral Reefs 24:360-369

Patterson HM, Swearer SE (2007) Long-distance dispersal and local retention of larvae as mechanisms of recruitment in an island population of a coral reef fish. Austral Ecol 32:122-130

> Patterson HM, Thorrold SR, Shenker JM (1999) Analysis of otolith chemistry in Nassau grouper (Epinephelus striatus) from the Bahamas and Belize using solution-based ICPMS. Coral Reefs 18:171-178

$>$ Patterson HM, Kingsford MJ, McCulloch MT (2004a) The influence of oceanic and lagoonal plume waters on otolith chemistry. Can J Fish Aquat Sci 61:898-904

> Patterson HM, Kingsford MJ, McCulloch MT (2004b) Elemental signatures of Pomacentrus coelestis otoliths at multiple spatial scales on the Great Barrier Reef, Australia. Mar Ecol Prog Ser 270:229-239

> Patterson HM, Kingsford MJ, McCulloch MT (2005) Resolution of the early life history of a reef fish using otolith chemistry. Coral Reefs 24:222-229

Quinn GP, Keough MJ (2002) Experimental design and data analysis for biologists. Cambridge University Press, Cambridge

Robertson DR (1973) Field observations on the reproductive behavior of a pomacentrid fish, Acanthochromis polyacanthus. Z Tierpsychol 32:319-324

> Rooker JR, Zdanowicz VS, Secor DH (2001) Otolith chemistry of tunas: assessment of base composition and post-mortem handling effects. Mar Biol 139:35-43

> Swearer SE, Caselle JE, Lea DW, Warner RR (1999) Larval retention and recruitment in an island population of a coral-reef fish. Nature 402:799-802

Thorrold SR, Latkoczy C, Swart PK, Jones CM (2001) Natal homing in a marine fish metapopulation. Science 291: 297-299

> Walther BD, Thorrold SR (2006) Water, not food, contributes the majority of strontium and barium deposited in the otoliths of a marine fish. Mar Ecol Prog Ser 311:125-130

- Williams DM (1982) Patterns of the distribution of fish communities across the central Great Barrier Reef. Coral Reefs 1:35-43

Wolanski E (2001) Oceanographic processes of coral reefs: physical and biological links in the Great Barrier Reef. CRC Press, Boca Raton, FL

> Wolanski E, Pickard GL (1983) Upwelling by internal tides and Kelvin waves at the continental shelf break on the Great Barrier Reef. Aust J Mar Freshw Res 34:65-80

Submitted: June 17, 2008; Accepted: October 24, 2008

Proofs received from author(s): February 11, 2009 